\title{
Measurements of Entrance Surface Dose and Effective Dose of Patients in Diagnostic Radiography
}

\author{
Sadeka Sultana Rubai ${ }^{1}$, Md Shakilur Rahman*2, Santunu Purohit ${ }^{1}$, Md Kawchar Ahmed Patwary ${ }^{3}$, AKM Moinul \\ Haque Meaze ${ }^{1}$ and Mamun AA $^{4}$
}

${ }^{1}$ Department of Physics, University of Chittagong, Chittagong, Bangladesh

${ }^{2}$ Secondary Standard Dosimetry Laboratory, Institute of Nuclear Science and Technology, Bangladesh Atomic Energy Research Establishment, Savar, Dhaka, Bangladesh

${ }^{3}$ Department of Physics, Comilla University, Comilla, Bangladesh

${ }^{4}$ Department of Physics, Jahangirnagar University, Savar, Dhaka, Bangladesh

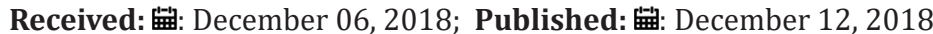

*Corresponding author: Md Shakilur Rahman, Secondary Standard Dosimetry Laboratory, Bangladesh Atomic Energy Commission, Savar, Dhaka, Bangladesh

\begin{abstract}
In radiography, a dose to patients primarily depends on the Entrance Surface Dose (ESD) and the sensitivity of organs which are irradiated during treatment plan. The main goal of this study is to look into the patient's dose to assess ESD and ED for patients in digital diagnostic radiography examinations for the optimization of radiation protection of the patients who are exposed to radiation dose thereby facing the increasing probability of fatal cancer risk and other biological effects. Patients dosimetry carried out on 15 adult patients (Male-4 and Female-11) of age 20 to 69 years. The IAEA TRS No. 457 dosimetry protocol was followed in accordance with non-invasive kV-meter, DIAVOLT UNIVERSAL T43014-001400, locating at $100 \mathrm{~cm}$ from focus to surface distance for measurement of radiological parameters such as $\mathrm{kVp}$ and $\mathrm{mAs}$. The ESD has a wide range from $0.05 \mathrm{mGy}$ to $0.35 \mathrm{mGy}$ for chest even for the same examination carried out on the patients of different age and gender and the corresponding effective dose lies from 0.01 to $0.04 \mathrm{mSv}$, additionally, in other parts like L-spine AP, Lat and in foot ESDs are $1.24 \mathrm{mGy}, 2.06 \mathrm{mGy}$ and 0.07 mGy respectively with their corresponding EDs are $0.13 \mathrm{mSv}, 0.05 \mathrm{mSv}$ and $0.0003 \mathrm{mSv}$. The ESDs and EDs reported in this study are generally lower than the doses published in literatures.
\end{abstract}

Keywords: Ionizing Radiation; X-Ray; Radiography; Entrance Surface Dose; Effective Dose

\section{Introduction}

Now-a-days, diagnostic X-ray examinations are very common and important source of all the medical exposures used in the medical diagnosis for world population [1]. Extensive demand of $\mathrm{X}$-ray examinations in the developing countries and the increases of the number of X-ray machines have driven the increase use of this. Therefore, it is of being crucial importance to enforce radiation protection following the principles of justifications, optimization and individual dose limits during radiographic projection for lessening the corresponding risks. Quality control and dose measurement help the physician and physicist to assure that the doses received by the radiographic patients should be in according to the principle of As Low as Reasonably Achievable (ALARA) and the dose does not exceed the amount required to get proper radiographic imaging [2]. Due to the ionizing nature of the X-rays which means that their use is not completely riskless, dose assessment is necessary to enhance the optimization of the radiation protection of the patients and to deliver minimum dose during examinations in the field of radiology [3].

As, X-rays are potentially harmful, the dose measurement is used either as a representative for radiation risk or as a step in actual estimation of the risk. A survey of personal performing ERCP found that patents as well as staff are also exposed to radiation which was equivalent to an estimated lifetime fetal cancer risk of between 1 in 3500 and 1 in 7000 [4]. It is therefore worthwhile that patient doses should be expressed in terms of a quantity which is closely related to radiation risk associated with X-ray examinations [5]. From this point of view, it is very important to figure out on what amount of radiation exposure has occurred during diagnosis in order to lessen extraneous radiation to patients [6]. Possibility of harm could estimate by quantifying the radiation received by patients who is undergoing X-ray examinations. In radiography, doses to patient depend on the Entrance Surface Dose (ESD), the 
sensitivity of the organs and tissues which being irradiated during the radiographic projections [7].

In this study, three common examinations are focused as their importance to investigate whether the ESDs are within the recommended value of International Atomic Energy Agency (IAEA) to keep the patient dose as low as possible. Moreover, investigation finished to measure the patients' dose who are undergoing X-ray examinations and the estimation of the lethal risk for cancer incidence. The results of this study would be beneficial to lessen the patients' dose and would be used as the value for the quality assurance in optimizing the patient dose specially for that projection which is not in the Diagnostic Reference Level (DRL) like EC and NRPB.

\section{Materials and Methods}

This study includes three commonly performed diagnostic X-ray examinations at two hospitals namely; Delta Hospital Ltd. and Institute of Cancer Research and Hospital (NIRCH), Dhaka, Bangladesh. These hospitals were selected because of the high workload of patient. These most frequently used examinations on which the measurements were conducted are chest (AP/PA/ LAT), L-Spine (AP/LAT) and Foot on 15 (male - 4 and female - 11) patients and they were selected from a larger group of patients. As for convenient study, the patients were selected randomly considering their age, weight, gender where most of the patients were recommended to check disorder of chest. Besides, there were also two patients where one was recommended to check fracture in foot and another was for disorder of L-Spine. The inherent filtration of X-ray machines of two hospitals were $1 \mathrm{~mm}$ and $1.5 \mathrm{~mm}$ Al respectively. The radiographic equipment's were digital and the examinations were performed by Shimadzu (IEC60601-1-2-2001) and Siemens (Siemens part8375545g2107) units. Before initiating the measurement, X-ray generator and equipment were tested for time accuracy, voltage accuracy, output linearity, filtration (HVL) using PTW DIAVOLT Universal T43014 as a part of quality control test. Dosimetry protocol in this study was in according to the IAEA Technical Report Series No. 457 [8]. The ESD for patients were determined by measuring air kerma in indirect method during the examination by using a calibrated $\mathrm{kVp}$ meter (PTW DIAVOLT Universal T43014). When the tube current, the exposure time and the focus to surface distance were known, ESD can be found by entering those parameters into the following formula [9]:

$$
E S D={ }_{n} K_{a}(U, F) \times(100 \mathrm{~cm} / F S D)^{2} \times P_{i t} \times B S F
$$

Where, is the tube output determined in units of at a distance of $100 \mathrm{~cm}$ from the focus to surface with voltage $U$ and total filtration F. FSD is the focus to surface distance $(\mathrm{cm})$, Pit is the tube current product used ( $\mathrm{mAs}$ ). BSF is the backscattering factor measured experimentally using Alderson Rando Phantom by taking different field sizes and tube voltages as well as photon energies into account. Effective energies were evaluated by using the established empirical formula which was obtained by the interpolation value from Hubble mass attenuation coefficients [10] and backscattering factor was used correspond to the measured effective energy. Patients' information including gender, weight, age, examination type and projection was also recorded. After determination of ESD, the Effective Dose (ED), E (mSv), is calculated by using the following formula [11]:

$$
E(m S v)=E S D(m G y) \times C C_{E S D}(m S v / m G y)
$$

Where CCESD is the conversion coefficient found from the report of NRPB-R262 [12] which relates ESD to ED. Risk factor was estimated by risk calculator using effective dose and other physical parameters of the patients [13].

\section{Results and Discussion}

The measurements of doses in this study were performed on adult patients and patients of extreme body weight have been excluded from the analysis. Table 1 shows a summary of the patients' information and the technical parameters selected for various types of examination which was prescribed in both hospitals. Information about patients like age, number of patients, gender, types of projection and also the examination of X-ray are summarized as well as tube current-time (mAs) product and the applied tube voltages for digital radiography are tabulated as the technical parameters.

\begin{tabular}{|c|c|c|c|c|c|c|}
\hline \multirow{2}{*}{ Projection } & \multirow{2}{*}{ Examination } & \multirow{2}{*}{ Patient age (year) } & \multicolumn{2}{|c|}{ No. of Patients } & \multicolumn{2}{|c|}{ Examination Technical Parameters } \\
\hline & & & Male & Female & kVp (mean) & mAs (mean) \\
\hline PA & Chest & $20-69$ & 4 & 8 & 66.48 & 12.63 \\
\hline AP & Chest & 50 & 0 & 1 & 62.40 & 20 \\
\hline Lat & Chest & 50 & 0 & 1 & 65.60 & 28 \\
\hline AP & L-spine & 55 & 0 & 1 & 71.40 & 40 \\
\hline Lat & L-spine & 55 & 0 & 1 & 76.90 & 56 \\
\hline- & Foot & 48 & 0 & 1 & 40.80 & 8 \\
\hline
\end{tabular}

Table 1: Summary of patients' information and examination technical parameters from digital radiographic examinations. 
It can be seen from Table 1 that the tube voltage used for different X-ray examinations varied with respect to the type of examination. Very High voltages were avoided in this study for few reasons. As the use of very high voltages can cause the damage of tubes, so it was avoided to use kVps more than 85 for adult patients of average sizes. In case of fatty patients that consideration may be changed. For each type of radiograph, ESD values for each patient were calculated for each set of dose measurement in both hospitals. For all examinations, the ages ranged from minimum of 20 years to the maximum 69 years in this work. Table 2 summarizes the key dosimetry parameters for three types of radiographic examinations with risk factor in this study.

Effective dose is evaluated as a dose descriptor in diagnostic radiology that enables a direct comparison of the detriment associated with different radiologic procedures. If patients' dose is expressed in terms of effective dose, it provides a congruent method of reporting effective doses from diagnostic radiologic examinations. The use of effective dose may also permit an estimate of patient risk to be obtained by using risk calculator. Table 2 also shows the risk factor for patients of different ages with different $x$-ray examination which is prescribed to them. For all x-ray examinations, ESD ranged from a minimum $0.05 \mathrm{mGy}$ to the maximum of $2.06 \mathrm{mGy}$ and the effective doses were $0.0003 \mathrm{mSv}$ to $0.13 \mathrm{mSv}$. The estimated ESDs compared with published works elsewhere and internationally established diagnostic reference level [3,14-20] and the estimated ED compared with published works elsewhere $[3,15,21,22]$ are shown in Tables $3 \& 4$ respectively. In this study the tube voltages used for different examinations were between 50 and $77.40 \mathrm{kVp}$ except in foot where the value is $40.80 \mathrm{kVp}$.

Table 2: Shows that in the same $x$-ray room and same projection there were variations in the ESD values which may be related to the patient size and the different technical parameters of radiological equipment used.

\begin{tabular}{|c|c|c|c|c|c|}
\hline Organ & Gender & $\begin{array}{l}\text { Entrance surface dose } \\
\text { (mGy) }\end{array}$ & $\begin{array}{c}\text { Age } \\
\text { (years) }\end{array}$ & $\begin{array}{l}\text { Effective dose } \\
\text { (mSv) }\end{array}$ & Risk factor (\%): incident per population \\
\hline Chest & Female & $0.1210 \pm 0.0050$ & 35 & 0.0120 & $1.35 \times 10^{-4}(1: 740741)$ \\
\hline Chest & Male & $0.1140 \pm 0.0040$ & 20 & 0.0110 & $1.27 \times 10^{-4}(1: 787402)$ \\
\hline Chest & Female & $0.1030 \pm 0.0030$ & 60 & 0.0100 & $4.8 \times 10^{-5}(1: 787402)$ \\
\hline Foot & Female & $0.0660 \pm 0.0020$ & 48 & 0.0003 & $2 \times 10^{-6}(1: 50000000)$ \\
\hline Chest & Male & $0.1360 \pm 0.0050$ & 54 & 0.0140 & $6.3 \times 10^{-5}(1: 1587302)$ \\
\hline Chest AP & \multirow{2}{*}{ Female } & $0.2210 \pm 0.0060$ & \multirow{2}{*}{50} & 0.0220 & $1.49 \times 10^{-4}(1: 671141)$ \\
\hline Chest Lat. & & $0.3480 \pm 0.0100$ & & 0.0350 & $2.37 \times 10^{-4}(1: 421941)$ \\
\hline Chest & Male & $0.1180 \pm 0.0040$ & 50 & 0.0120 & $6.1 \times 10^{-5}(1: 1639344)$ \\
\hline Chest & Female & $0.1100 \pm 0.0040$ & 35 & 0.0110 & $1.24 \times 10^{-4}(1: 806452)$ \\
\hline Chest & Female & $0.0750 \pm 0.0020$ & 45 & 0.0080 & $6.4 \times 10^{-5}(1: 806452)$ \\
\hline L-Spine AP & Female & $1.2400 \pm 0.0410$ & 55 & 0.1330 & $7.58 \times 10^{-4}(1: 131926)$ \\
\hline L-Spine Lat & & $2.0600 \pm 0.0810$ & & 0.0520 & $2.97 \times 10^{-4}(1: 336700)$ \\
\hline Chest & Female & $0.0450 \pm 0.0010$ & 32 & 0.0050 & $6.2 \times 10^{-5}(1: 131926)$ \\
\hline Chest & Male & $0.0750 \pm 0.0040$ & 66 & 0.0080 & $2.6 \times 10^{-5}(1: 3846154)$ \\
\hline Chest & Female & $0.0600 \pm 0.0020$ & 55 & 0.0060 & $3.4 \times 10^{-5}(1: 2941176)$ \\
\hline Chest & Female & $0.1660 \pm 0.0050$ & 45 & 0.0170 & $1.36 \times 10^{-4}(1: 806452)$ \\
\hline Chest & Female & $0.2160 \pm 0.0060$ & 69 & 0.0220 & $7.8 \times 10^{-5}(1: 131926)$ \\
\hline
\end{tabular}

Table 3: ESDs for various X-ray examinations compared with radiographic procedures surveyed in other countries and DRLs.

\begin{tabular}{|c|c|c|c|c|c|c|c|c|c|}
\hline \multirow[b]{2}{*}{ Projection } & \multirow[b]{2}{*}{ Examination } & \multirow[b]{2}{*}{$\begin{array}{c}\text { ESD in } \\
\text { Present } \\
\text { study }\end{array}$} & \multicolumn{4}{|c|}{ ESD in Previous work } & \multicolumn{3}{|c|}{ DRL } \\
\hline & & & $\begin{array}{c}\text { D. Hart et } \\
\text { al., } 2012 \\
{[14]}\end{array}$ & $\begin{array}{c}\text { Ernest et } \\
\text { al., } 2012 \\
\text { [15] }\end{array}$ & $\begin{array}{l}\text { Al-Kinani et } \\
\text { al., 2014 } \\
\text { [16] }\end{array}$ & $\begin{array}{c}\text { Rasuli et al., } \\
2016 \\
{[17]}\end{array}$ & $\begin{array}{c}\text { EC } \\
(1999) \\
{[18]}\end{array}$ & $\begin{array}{c}\text { IAEA } \\
(1996) \\
{[19]}\end{array}$ & $\begin{array}{c}\text { NRPB } \\
(2000) \\
{[20]}\end{array}$ \\
\hline $\mathrm{AP}$ & Chest & 0.2210 & 0.16 & 0.57 & - & 1.12 & - & - & - \\
\hline Lat & Chest & 0.3480 & 0.48 & 0.94 & 1.73 & 2.20 & 1.5 & 1.5 & 1.0 \\
\hline $\mathrm{PA}$ & Chest & 0.1100 & 0.12 & 0.14 & 0.64 & 1.0 & 0.3 & 0.4 & 0.2 \\
\hline AP & L-Spine & 1.2400 & 4.6 & 3.72 & 13.3 & 3.09 & 10 & 10 & 6 \\
\hline Lat & L-Spine & 2.0600 & 7.9 & 6.28 & 35.97 & 7.5 & 30 & 30 & 14 \\
\hline- & Foot* & 0.0660 & - & - & - & - & - & - & - \\
\hline
\end{tabular}

*The ESDs value in foot is 0.1 which is given by M. T. Taha et al., 2015 [3]. 
Table 4: Comparison of ED for representative radiographic examinations.

\begin{tabular}{|c|c|c|c|c|c|c|}
\hline \multirow[b]{2}{*}{ Projection } & \multirow[b]{2}{*}{ Examination } & \multirow[b]{2}{*}{ ED in Present study (mSv) } & \multicolumn{4}{|c|}{ ED in Previous work(mSv) } \\
\hline & & & $\begin{array}{c}\text { D. hart et } \\
\text { al.,2002 [21] }\end{array}$ & $\begin{array}{l}\text { Mettler et al.,2008 } \\
{[22]}\end{array}$ & $\begin{array}{c}\text { Ernest et al.,2012 } \\
\text { [15] }\end{array}$ & $\begin{array}{l}\text { M.T. Taha et } \\
\text { al.,2015 [3] }\end{array}$ \\
\hline $\mathrm{AP}$ & Chest & 0.0220 & - & 0.1 & 0.066 & - \\
\hline Lat & Chest & 0.0350 & - & 0.1 & 0.11 & - \\
\hline $\mathrm{PA}$ & Chest & 0.0110 & 0.016 & 0.02 & 0.0204 & 0.018 \\
\hline AP & L-Spine & 0.1330 & 1.0 & 1.5 & 0.38 & - \\
\hline Lat & L-Spine & 0.0520 & 1.0 & 1.5 & 0.13 & - \\
\hline- & Foot & 0.0003 & 0.0005 & - & - & 0.001 \\
\hline
\end{tabular}

The range of mAs used for most X-ray examinations performed on patients were from 8 to $56 \mathrm{mAs}$, it can be seen that the exposure factor used for patients in this study is not comprised of very high voltages and mAs is low. The ESD (mGy) for all examinations are lower than that reported by IAEA [19] and European Committee (EC, 1999) [18] as well as NRPB -2000 [20] due to the use of a low tube current. But, for chest PA it is very close to the recommended value. With the increase of tube potential, the value of ED will increase thereby increasing ESD. The ESD value in chest PA is closely related to the value of M. T. Taha et al. [3] and D. Hart et al. [21]. Estimated value of an ED in foot is very closely related to the value given by D. Hart et al. [21] and M. T. Taha et al. [3]. For chest AP, ED is related to Ernest K. Osei [15]. For other X-ray exposure the value of ED is lower than that mentioned in Table 4.

\section{Conclusion}

The ESD measured indirectly does not exceed the values which are recommended by the international organizations. ESD values differ in the same X-ray room due to the patient size as well as exposure parameters because of maintaining the stability. Though due to short duration only three examinations were focused, further study is required for other X-ray examinations. As $\mathrm{X}$-rays are prescribed in a large number to check the condition of chest for getting information about any diseases or in case of any accidental case, proper care is needed during conducting such kind of examination. For Chest AP there is no DRL. So, this study will be useful in establishing DRL recommended by EC and IAEA as well as NRPB which will help delivering dose to patients during this projection (Anterior to Posterior). This study also contained data about foot on which a few survey has been done that will help in establishing DRL because there are no international recommended values for foot and it will stand for the present condition about foot. This will help in providing compact information about patients' whole body dose that is ED during examination of different projection of organs which is difficult to get in other references. There is also information about risk factor which is required to create awareness in using this radiography system.

\section{References}

1. Charles M (2001) UNSCEAR report 2000: Sources and effects of ionizing radiation. United nations scientific comittee on the effects of atomic radiation. J Radiol Prot 21(1): 83-86.
2. Rasuli B, Mahmoud-Pashazadeh A, Ghorbani M, Juybari RT, Naserpour M (2016) Patient dose measurement in common medical X-ray examinations in Iran. J Appl Clin Med Phys 17(1): 374-386.

3. Taha MT, Al-Ghorabie FH, Kutbi RA, Saib WK (2015) Assessment of entrance skin doses for patients undergoing diagnostic x-ray examinations in King Abdullah Medical city, Makkah, KSA. J Radiat Res Appl Sci 8(1): 100-103.

4. Naidu LS, Singhal S, Preece DE, Vohrah A, Loft DE (2005) Radiation exposure to personnel performing endoscopic retrograde cholangiopancreatography. Postgrad Med J 81(960): 660-662.

5. Le Heron JC (1992) Estimation of effective dose to the patient during medical $x$-ray examinations from measurements of the dose-area product. Phys Med Biol 37(11): 2117-2126.

6. Sorop I, Dadulescu E (2011) Assessment of entrance surface doses for newborn babies with an intensive care unit. Romanian Reports Physics 63(2): 401-410.

7. Fujibuchi T, Kato H, Hashimoto M, Abe Y, Kikawa T (2006) Characteristic evaluation of a real-time silicon dosimeter and measurement of entrance surface dose at radiography. Nihon Hoshasen Gijutsu Gakkai Zasshi 62(7): 997-1004.

8. IAEA (2007) Dosimetry in diagnostic radiology: An international code of practice. Technical Reports Series No. 457.

9. Sun I Kim, Tae S Suh (2006) World congress on medical physics and biomedical engineering. Springer Science \& Business Media, Korea pp. 586.

10. Rahman MS, Sujimura N, Yoshida TY (2008) Characterization of calibration x-ray fields in establishing operational quantities for the AIST middle Beam spectrum series. Bangladesh J Phys 5(6): 39-45.

11. Bahreyni Toosi MT, Nazery M, Zare H (2006) Application of dose-area product compared with three other dosimetric quantities used to estimate patient effective dose in diagnostic radiology. Int J Radiol 4(1): 21-28.

12. Wade JP (1998) Estimation of effective dose in diagnostic radiology from entrance surface dose and dose-area product measurements. Br J Radiol 71(849): 994-995.

13. http://www.xrayrisk.com/calculator/calculator.php

14. Hart D, Hillier MC, Shrimpton PC (2012) Doses to Patients from radiographic and fluoroscopic X-ray imaging procedures in the UK-2005 Review. Tech Rep HPA-RPD-029.

15. Ernest K Osei, Johnson Darko (2012) A survey of organ equivalent and effective doses from diagnostic radiology procedures. ISRN Radiology 2013: 1-9.

16. Al-Kinani AT, Mohsin Y (2014) Study of the quality assurance of conventional X-ray units at medical city in Baghdad. Arab J Nuclear Sci Appl 47(2): 129-137. 
17. Rasuli B, Ghorbani M, Juybari RT (2016) Radiation dose measurement for patients undergoing common spine medical x-ray examinations and proposed local diagnostic reference levels. Radiation Measurement 87: 29-34.

18. Carmichael JH E, Moores BM, Maccia C (1996) European guidelines on quality criteria for diagnostic radiographic images. European Commission.

19. International Labour Organization (1996) International basic standards for protection against ionizing radiation and for the safety of radiation source. IAEA Safety Series No. 115.

\section{ISSN: 2574-1241}

DOI: $10.26717 / B J S T R .2018 .12 .002186$

Md Shakilur Rahman. Biomed J Sci \& Tech Res

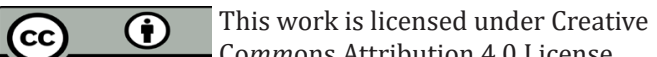

Submission Link: https://biomedres.us/submit-manuscript.php
20. National Radiologic Protection Board (2002) National protocol for patient dose measurements in diagnostic radiology. Chilton Didcot, UK.

21. Hart D, Wall BF (2002) Radiation Exposure of the UK population from Medical and Dental X-ray Examinations. Tech Rep NRPB-W14 p. 1-61.

22. Mettler FA, Huda W, Yoshizumi TT, Mahesh M (2008) Effective doses in radiology and diagnostic nuclear medicine: A catalog. Radiology 248(1): 254-263.

$\begin{array}{ll}\text { BIOMEDICAL } & \text { Assets of Publishing with us } \\ \text { RESEARCHES } & \text { - Global archiving of articles } \\ & \text { - Immediate, unrestricted online access } \\ & \text { - Rigorous Peer Review Process } \\ \end{array}$

